\title{
Mothers' Satisfaction Regarding Emergency Nursing Care of their Children
}

\author{
Sahar Mahmood El-Khedr \\ Lecturer of Pediatric Nursing, \\ Faculty of Nursing, Tanta University.
}

\begin{abstract}
Background: Patient satisfaction is considered an important indicator of the quality of care from the perspective of the consumer. There is a growing interest in patient satisfaction as an outcome of care. Parents satisfaction "especially mothers" with a pediatric practice is very important because mothers are always involved in medical treatment of their children. Satisfied patients are more likely to comply with treatment, take an active role in their own care. There is evidence that satisfaction with pediatric medical visits is related to parents' compliance with medical regimes, understanding and retention of medical information, and continuity of care . Few studies have examined patients' satisfaction with emergency nursing services. Pediatric patients who seek emergency care require skilled and timely assessments by experienced emergency care nurses. The study aims to assess mothers' satisfaction regarding emergency nursing care of their children. This is a descriptive study design, that was carried out at Tanta Emergency Hospital. Convenient sample of eighty children and their mothers were involved in the study. One tool was used to collect data, the first part was a questionnaire sheet to assess socio-demographic data about children and their mothers. A second part was a Consumer Emergency Satisfaction Scale (CESS). The results of this study revealed, statistical significant difference in the total nursing care and total education. Statistical significant correlation was detected between professional qualities and both nurses' attitudes and the way the nurse welcome the mothers and their children. It is recommended that further researches are needed to capture pediatric children opinions about the emergency care provided to them. Application of triage system in emergency room to improve the quality of care.
\end{abstract}

Key words: Emergency nursing care, Mothers' satisfaction. 


\section{Introduction}

Satisfaction can be defined as the extent of an individual's experience compared with his / her expectations. Evaluating to what extent patients are satisfied with health services is clinically relevant. Satisfied patients are more likely to comply with treatment and, take an active role in their own care. They continue using medical care services, stay within a health care provider and maintain with a specific system. In addition, health professionals may benefit from satisfaction surveys that identify potential areas for service improvement and health expenditure may be optimized through patientguided planning and evaluation ${ }^{(1)}$

Satisfaction is not some pre-existing phenomenon waiting to be measured, but a judgment، people form over time as they reflect on their experience. Patients' satisfaction with health care they received becomes a priority issue. $^{(2)}$ Satisfaction is increasingly being linked with improvements in the quality of health care and improved health outcomes. There is an increasing impetus for shared decision making and person centered care. It is considered an important indicator of quality care from the perspective of the consumer. ${ }^{(3)}$
Patient satisfaction is defined as the perception of patient needs and expectations being met. It is rapidly becoming a primary indicator for evaluation and comparison of quality in health care plans. Patient satisfaction, or parent satisfaction in case of children under medical care, is a construct from social research, which describes the satisfaction of patients with demanded services from the health care system. ${ }^{(4,5)}$ Specifically the term "patient satisfaction" is described by the discrepancy between the quality of the medical care expected from the patient and the perceived quality of medical treatment. The special aspect of the concept of patient satisfaction is that quality standards are not evaluated any more by teams of experts but by the patients themselves. ${ }^{(5)}$

Quality assessment studies usually measure one of three types of outcomes: medical outcomes, costs, and client satisfaction. Patients are asked to assess not only their own health status after receiving care but also, their satisfaction with the services delivered.

Mothers satisfaction with nursing care provided to their children is very important because it can be used as an 
indicator of the quality of care. Mothers are also involved in medical treatment of their children. It is indispensable that the nurses includes the parents in the treatment regime and the care of their children. Compliance with medical regimen and understanding of medical information are the major responsibility of the parents especially mothers. ${ }^{(6)}$

Satisfied mothers are more likely to be compliant and cooperative. Monitoring and evaluating consumer satisfaction with health care is a crucial input in improving the quality of health system and changes in the system as well as providing feedback for health care professionals and policy makers. Measures of consumer satisfaction with health care can provide important assessment of quality of health care not adequately captured by other health service statistics such as patient throughput, waiting times, consultation times and proximity. In fact, it has been suggested that patient satisfaction is a major quality outcome in itself. ${ }^{(7)}$

Emergency care continues to be a challenge for the pediatric population. Children who seek emergency care require skilled and timely assessments by experienced emergency nurses. Emergency Nursing is a nursing specialty in which nurses care for patients in the emergency or critical phase of their illness or injury. ${ }^{(8,9)}$ Nationwide, there are an estimated 30 million Emergency Department (ED) visits per year for patients under 18 years of age, accounting for one-fourth of all ED visits. Egypt has assigned top priority to the improvement of its standard of pediatric care since 1979. Egypt was still suffering from a high mortality rate of children under five. The cause of death was mainly from curable diseases such as respiratory infections and diarrhea. Had it not been for the delay of appropriate treatment, the lives of a significant number of children could have been saved. while the quality of pediatrics had reached almost a satisfactory level, the emergency medical services had been neglected. ${ }^{(10)}$

The process of care in the emergency department can vary depending on country or hospital size. The characteristics of the patient in the emergency department can also vary due to a wide variation in presenting illnesses, injuries and mental states. The patients also differ in age, from young children to elderly people. Attending the emergency department is an unplanned situation and the patient is usually 
experiencing pain, fear and/or anxiety. Sometimes life-saving procedures are needed. However, for most patients in the emergency department, minor medical interventions are sufficient. Common reasons for children seeking emergency care include asthma, fever, diarrheas, pain, allergies, fractures and broken bones, and trauma. The patient's transit time can range from a few minutes to several hours and depends on patient flow, which fluctuation the patients' reasons for attending the emergency department and the need for more or less urgent medical attention. ${ }^{(11)}$ Overcrowded emergency departments mean long waiting times. Patients with non-urgent health-related problems are often classified as inappropriate patients in the emergency department. ${ }^{(12)}$ On the other hand, the inability to obtain access to primary care is a common reason for non-urgent patients to attend the emergency department ${ }^{(13,14)}$ Long wait times may also lead to some patients leaving the emergency department without being seen by a physician. This is a threat to patient safety and the quality of care in emergency departments. ${ }^{(15)}$ Nurses in the emergency department spend less than half of their time on direct patient care tasks. The role of the emergency nurse is expanding, with demands for advanced skills, monitoring and documentation. ${ }^{(16)}$

Nurses in the ED are responsible for meeting the various needs of their pediatric patients. The nurse also, needs to consider that, children physiological and psychological responses to stressors are not the same as those of adults. Treatment plans varies according to the acuteness and problems presented by the children. Educating children and their mothers about their condition and treatment, addressing effective means of self-care and adaptation to change in lifestyle, and if necessary, discussing ways to prevent recurrence of sickness are integral parts of the plan of care. A hospital ED is recognized as the front door where a significant number of inpatient admissions take place. The tremendous increase in the number of patients visiting ED has contributed to patient dissatisfaction. Satisfaction with the health care services and health care provider is a predictor of overall patient satisfaction. (17)

\section{Subjects and Method}

\section{Subjects}

\section{Design:}

This is a descriptive study design that was 
used to assess the mothers' satisfaction regarding emergency nursing care of their

Setting:

Tanta Emergency hospital.

\section{Sample:}

A convenient sample of 80 mothers of children under 12 years who admitted to Pediatric Emergency Department of Tanta Emergency Hospital, over a period of three months. The mothers who fulfilled the following criteria were included in the study:

1- Mothers' ages ranged from 25-45 years.

2- Free from any communication or psychological problems

Tools: A questionnaire sheet was used in this study. It consisted of two parts. The first part of the tool was developed by the researcher to collect sociodemographic data about the children and their mothers involved in this study, it included children's ages, gender, and medical history. Mothers age, level of education, and occupation were also assessed. The second part of the tool was Consumer Emergency Care Satisfaction Scale (CECSS). It was developed by Davis in 1988 and revised in 1997 to examine patient satisfaction to nursing care. ${ }^{(18,19)}$ The CECSS tool was consisted 12 items that demonstrated assessment of nursing care, while teaching is recorded in 3 items. The CECSS also contains four negatively worded filter items to minimize response set bias. It was classified into five-point Likert-type rating scale demonstrating the degree of satisfaction with each statement. Possible responses ranged from strongly disagree (1) to strongly agree (5). A higher score represents a higher degree of satisfaction with ED nursing. A total score of more than $60 \%$ indicated satisfaction, while the score less than $60 \%$ indicated dissatisfaction. A pilot study was conducted on 8 of mothers minor modifications were made to the questionnaires. Also validity and reliability of the questionnaires were tested.

\section{B-Methods:}

\section{Data collection:}

The researcher collected data from Tanta Emergency Hospital. Approval was taken from the responsible authorities before starting to collect data. Ethical consideration of privacy, confidentiality, and the rights of the mothers to withdraw from the study at any time were also considered. 
Interview was conducted with mothers. Simple explanation about the aim of the study was done for them. Those who agreed to participate were involved in the study, before discharging from the Emergency Hospital.

\section{Statistical analysis}

SPSS software package version 17 was used for statistical analysis. Simple frequencies mean, standard deviation, $\chi^{2}, \mathrm{P}$ test and Pearson' correlations were used when appropriate.

\section{Results}

Figure (1) shows distribution of children' age . It was clear that nearly two third of children (32.5\%) aged from $7<10$ years. One quarter of children (25\%) aged between 10-12 years while, $20 \%$ and $22.5 \%$ of the children aged between $1<4$ year and $4<7$ years respectively. The mean age of children was $5.21 \pm 3.52$.

As regards table (1), nearly equal percent of the mothers $(26.25 \%$ and 25 $\%)$ aged from $30<35$ years and between 40 - 45 years respectively. The mean age of the mothers was $32.02+7.43$. Slightly less than half of the mothers $(46.25 \%)$ had diplomat degree. Twenty seven point five were illiterate and $20 \%$ had bachelor degree.
Almost, three quarters of the mothers (72.5\%) were house wife compared by $12.5 \%$ and $15 \%$ who were worker and employees respectively.

Mothers ' satisfaction about nurses attitudes and nursing care received were illustrated in table (2). Equal percent of the mothers $(18.75 \%)$ described nurses attitudes as either genuine or caring. Twenty eight point seventy five of the mothers reported that nurses were helpful. Nearly three quarters of the mothers $(73.75 \%)$ mentioned that their children received basic nursing intervention , compared by $26.25 \%$ of the mothers who reported that, their children received specific nursing intervention. Forty one point twenty five percent of the nurses were efficient, $28.75 \%$ were knowledgeable and $18.75 \%$ of the nurses were treating everyone equally according to mothers description. Nearly half of the mothers $(48.75 \%)$ mentioned that the nurses were welcomed them in a good way compared to $33.75 \%$ of the mothers who said that nurses were welcomed them in a bad manner while receiving their children. Statistical significant differences were found in mothers satisfaction with nursing care, nurses 
professional qualities and the way nurses welcome them while receiving them.

Figure (2) shows the distribution of mothers according to waiting time, It was evident that, slightly less than half of the mothers waiting between $45<60$ minutes. Eighty eight point seventy five percent were waiting more than 60 minutes compared by $18.75 \%$ and $7.5 \%$ who waited between $30<45 \mathrm{~min}$. and < 30 minutes respectively. The mean of waiting time was $51.31+19.61$.

Table (3) shows mothers ' satisfaction according to CECSS. It was clear that, three quarters of the mothers were satisfied by the nursing care provided to their children. They mentioned that the nurses know something about my illness, explained things in terms that they could understand. Nurses were understanding when listening to children's problems and, appeared to take time to meet their needs were reported by the same percent $(75 \%)$ of mothers. Sixty five percent of the mothers mentioned that, the nurses explained procedures before they were done and $60 \%$ of the mothers reported that, the nurses were sure that all their questions were answered. Statistical significant difference was found in the total nursing care provided to children $(\mathrm{P}=0.000)$. Three quarters of the mothers reported satisfaction with the health teaching provided to them and their children. They mentioned that, nurses told them about the children's problems and, the expectation that may occur at home. Statistical significant difference was found regarding total teaching $(\mathrm{P}=0.000)$.

Mothers overall satisfaction regarding emergency visit was evident in table (4). It was clear that, nearly equal percent of $41.25 \%$ and $40 \%$ of the mothers were reported good and fair satisfaction with the emergency visit. There was statistical significant difference $\quad(\mathrm{P}=0.022)$ Mothers mentioned that, they like the service, environment, nurses behavior and flexibility, the percentage of the responses were $25 \%, 22.5 \%, 28.75 \%$ and $23.75 \%$ respectively. Nearly one third of the mothers (35\%) recommended to enhance the waiting room. Twenty five percent recommended to increase the number of nursing staff .

As regards table (5), statistical significant correlation was found 
between the satisfaction of total care and mothers education. Negative correlation was found between education, occupation, and satisfaction with waiting time. Also, negative correlations were found between mothers occupation and satisfaction with both total care and total education.

Table (6) shows the correlations between mothers satisfaction with nurses professional characteristics, total care and total teaching. As regards, there was significant correlation between total care and total teaching. Regarding the correlation between the waiting time and total care, there was negative correlation that was statistically insignificant, this means that, with the increasing waiting time the satisfaction with total nursing care was decrease. Negative correlation also observed between nurses attitude and total nursing care that means that, negative attitudes leads to dissatisfaction with total care. Statistical significant correlations were detected between professional quality and nurses attitudes and between professional quality and the way the nurse welcome the mothers and their children.

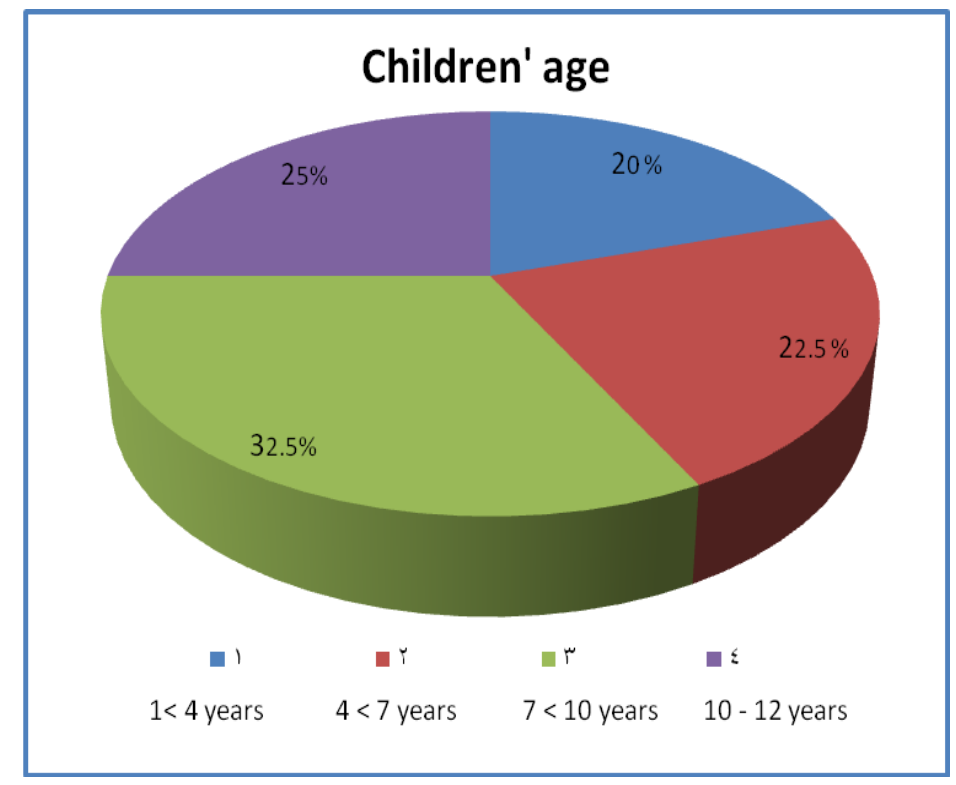

Figure (1) Distribution of children according to age. 
Table 1. Percent distribution of mothers according to demographic data .

\begin{tabular}{|c|c|c|}
\hline Items & n. $=80$ & $\%$ \\
\hline \multicolumn{3}{|l|}{ Age in years: } \\
\hline $20-$ & 13 & 16.25 \\
\hline $25-$ & 18 & 22.5 \\
\hline $30-$ & 21 & 26.25 \\
\hline $35-$ & 8 & 10 \\
\hline $40-45$ & 20 & 25 \\
\hline \multicolumn{3}{|c|}{ Mean \pm SD $=32.02+7.43$} \\
\hline \multicolumn{3}{|l|}{ Education: } \\
\hline Illiterate & 22 & 27.5 \\
\hline Diplomat & 37 & 46.25 \\
\hline Bachelor & 16 & 20 \\
\hline Post graduate & 5 & 6.25 \\
\hline \multicolumn{3}{|l|}{ Occupation } \\
\hline House wife & 58 & 72.5 \\
\hline Worker & 10 & 12.5 \\
\hline Employee & 12 & 15 \\
\hline
\end{tabular}

Table 2. Percent distribution of mothers according to satisfaction about nurses attitudes and nursing care received.

\begin{tabular}{|c|c|c|c|c|}
\hline Items & $\mathrm{n}_{.}=80$ & $\%$ & $\chi^{2}$ & $\mathbf{P}$ \\
\hline $\begin{array}{l}\text { Nurses attitudes } \\
\text { Genuine } \\
\text { Calm } \\
\text { Helpful } \\
\text { Caring } \\
\text { Understanding } \\
\end{array}$ & $\begin{array}{l}15 \\
16 \\
23 \\
15 \\
11 \\
\end{array}$ & $\begin{array}{l}18.75 \\
20 \\
28.75 \\
18.75 \\
13.75 \\
\end{array}$ & 4.750 & 0.314 \\
\hline $\begin{array}{l}\text { Received nursing care } \\
\text { Basic nursing intervention } \\
\text { Specific intervention }\end{array}$ & $\begin{array}{l}59 \\
21\end{array}$ & $\begin{array}{l}73.75 \\
26.25\end{array}$ & 18.05 & $0.000 *$ \\
\hline $\begin{array}{l}\text { Professional Qualities of Nurse: } \\
\text { Efficient, } \\
\text { Knowledgeable } \\
\text { Privacy respected } \\
\text { Treated everyone equally } \\
\end{array}$ & $\begin{array}{c}33 \\
23 \\
9 \\
15\end{array}$ & $\begin{array}{l}41.25 \\
28.75 \\
11.25 \\
18.75\end{array}$ & 16.20 & $0.001 *$ \\
\hline $\begin{array}{l}\text { Nurses welcomed the patients: } \\
\text { Very Good } \\
\text { Good } \\
\text { Bad }\end{array}$ & $\begin{array}{l}14 \\
39 \\
27\end{array}$ & $\begin{array}{c}17.5 \\
48.75 \\
33.75\end{array}$ & 11.72 & $0.003 *$ \\
\hline
\end{tabular}

$*$ Significant at $\leq 0.05$ level. 


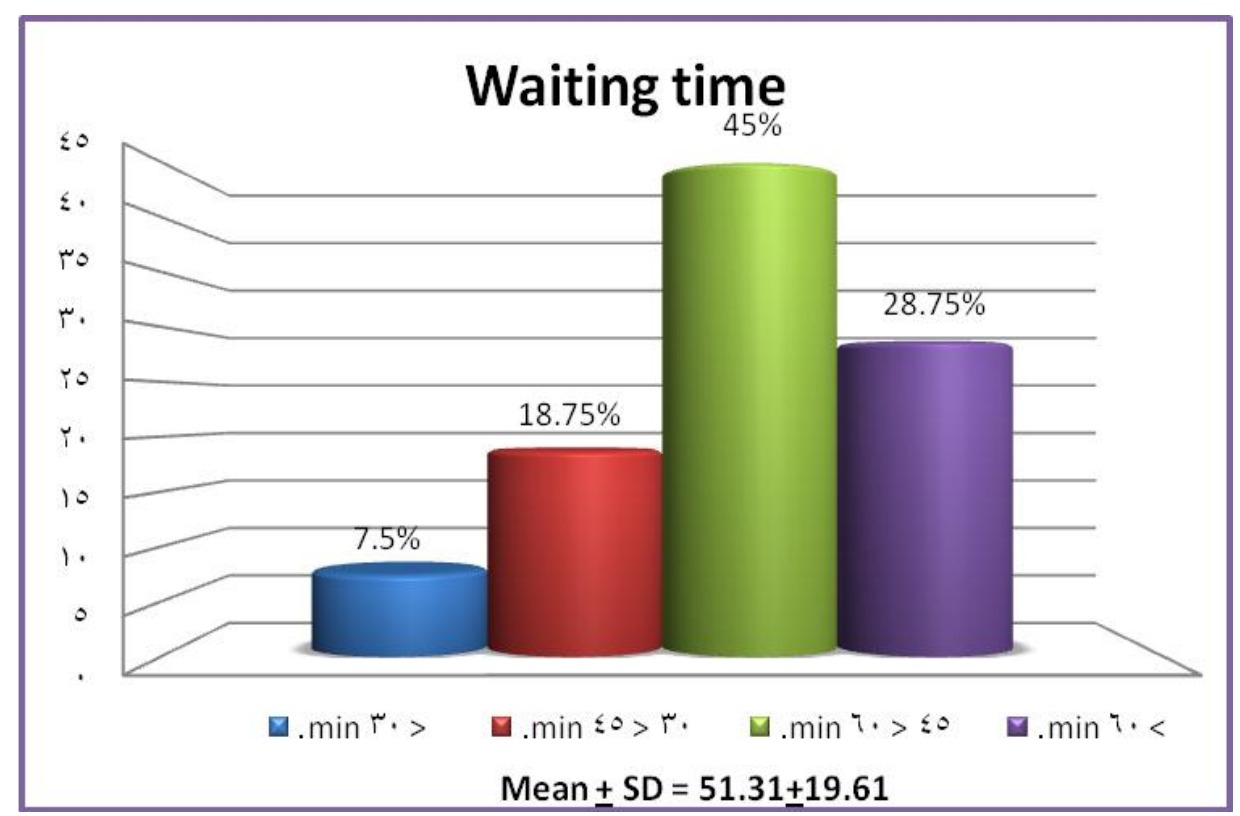

Figure (2) Distribution of mothers according to waiting time

Table 3. Percent distribution of mothers according to satisfaction according to Consumer Emergency Care Satisfaction Scale (CECSS) .

\begin{tabular}{|c|c|c|c|c|c|}
\hline & \multicolumn{2}{|c|}{ Satisfied } & \multicolumn{2}{|c|}{ Unsatisfied } \\
\hline & & $\mathbf{n}=\mathbf{8 0}$ & $\%$ & $\mathrm{n}=\mathbf{8 0}$ & $\%$ \\
\hline 1 & $\begin{array}{l}\text { Caring: } \text { The nurse.... } \\
\text { performs her duties with skill. }\end{array}$ & 30 & 37.5 & 50 & 62.5 \\
\hline 2 & knows something about child's illness. & 60 & 75 & 20 & 25 \\
\hline 3 & knows what treatment child' need. & 44 & 55 & 36 & 45 \\
\hline 4 & explained procedures before they were done. & 52 & 65 & 28 & 35 \\
\hline 5 & explained things in terms that I could understand. & 60 & 75 & 20 & 25 \\
\hline 6 & understand when listening to child's problem. & 60 & 75 & 20 & 25 \\
\hline 7 & seems genuinely concerned about child's pain. & 40 & 50 & 40 & 50 \\
\hline 8 & is gentle when performing painful skill. & 50 & 62.5 & 30 & 37.5 \\
\hline 9 & seems to understand how child's felt. & 62 & 77.5 & 18 & 22.5 \\
\hline 10 & gives me a chance to ask questions. & 40 & 50 & 40 & 50 \\
\hline 11 & appears to take time to meet child's needs. & 60 & 75 & 20 & 25 \\
\hline 12 & sure that all my questions were answered. & 48 & 60 & 32 & 40 \\
\hline \multicolumn{6}{|c|}{$\begin{array}{lr}\text { Total Nursing care } & \chi^{2} / 38.80 \\
& 0.000 *\end{array}$} \\
\hline 1 & $\begin{array}{l}\text { Teaching: The nurse.... } \\
\text { instructs me about home self care }\end{array}$ & 40 & 50 & 40 & 50 \\
\hline 2 & tells me about my problems & 60 & 75 & 20 & 25 \\
\hline 3 & tells me what to expect at home & 60 & 75 & 20 & 25 \\
\hline
\end{tabular}

$*$ Significant at $\leq 0.05$ level. 
Table 4. Percent distribution of the overall mothers' satisfaction about their ER visit.

\begin{tabular}{|c|c|c|c|c|}
\hline Items & $\mathrm{n}=\mathbf{8 0}$ & $\%$ & $2^{\chi}$ & $\mathbf{P}$ \\
\hline $\begin{array}{l}\text { 1) Emergency visit } \\
\text { - Good } \\
\text { - Fair } \\
\text { - Poor } \\
\end{array}$ & $\begin{array}{l}33 \\
32 \\
15\end{array}$ & $\begin{array}{c}41.25 \\
40.0 \\
18.75\end{array}$ & 7.67 & $0.022 *$ \\
\hline $\begin{array}{l}\text { 2)What did you like in ER? } \\
\text { - Service } \\
\text { - Environment } \\
\text { - Nurse behavior } \\
\text { - } \quad \text { Flexibility }\end{array}$ & $\begin{array}{l}20 \\
18 \\
23 \\
19\end{array}$ & $\begin{array}{r}25.0 \\
22.5 \\
28.75 \\
23.75\end{array}$ & 0.70 & 0.873 \\
\hline $\begin{array}{l}\text { 3) Efforts to enhance emergency } \\
\text { - Increase number of nursing staff } \\
\text { - Large Wating room } \\
\text { - Increase number of equipment } \\
\text { - } \quad \text { Presence of doctors all time } \\
\end{array}$ & $\begin{array}{l}20 \\
28 \\
14 \\
18\end{array}$ & $\begin{array}{l}25.0 \\
35.0 \\
17.5 \\
22.5\end{array}$ & 5.20 & 0.158 \\
\hline
\end{tabular}

*Significant at $\leq 0.05$ level.

Table 5. Correlations between mothers socio-demographic data and satisfaction with total care, total education and waiting time.

\begin{tabular}{|c|c|c|c|c|c|c|}
\hline \multirow{2}{*}{ Items } & \multicolumn{2}{|c|}{ Waiting time } & \multicolumn{2}{c|}{ Total care } & \multicolumn{2}{c|}{ Total education } \\
\cline { 2 - 7 } & $\mathbf{R}$ & $\mathbf{P}$ & $\mathbf{r}$ & $\mathbf{P}$ & $\mathbf{r}$ & $\mathbf{P}$ \\
\hline Mothers' age & 0.032 & 0.777 & -0.090 & 0.427 & 0.010 & 0.928 \\
\hline Education & -0.096 & 0.397 & 0.220 & $0.050^{*}$ & 0.071 & 0.532 \\
\hline Occupation & -0.075 & 0.507 & -0.030 & 0.793 & -0.011 & 0.922 \\
\hline
\end{tabular}


Table 6. Correlation matrix between mothers' satisfaction with nurses professional characteristics and total care and total teaching.

\begin{tabular}{|c|c|c|c|c|c|c|c|}
\hline \multicolumn{2}{|l|}{ Items } & Total care & $\begin{array}{c}\text { Total } \\
\text { teaching }\end{array}$ & $\begin{array}{c}\text { Waiting } \\
\text { Time }\end{array}$ & $\begin{array}{l}\text { Nurses } \\
\text { attitude }\end{array}$ & $\begin{array}{c}\text { Received } \\
\text { care }\end{array}$ & $\begin{array}{l}\text { Profession } \\
\text { al quality }\end{array}$ \\
\hline \multirow{2}{*}{ Total teaching } & $\mathbf{R}$ & 0.311 & - & - & - & - & - \\
\hline & $\mathbf{P}$ & $0.005^{* *}$ & - & - & - & - & - \\
\hline \multirow{2}{*}{ Waiting time } & $\mathbf{R}$ & -0.139 & 0.022 & - & - & - & - \\
\hline & $\mathbf{P}$ & 0.219 & 0.847 & - & - & - & - \\
\hline \multirow{2}{*}{ Nurses attitude } & $\mathbf{R}$ & -0.029 & 0.019 & -0.085 & - & - & - \\
\hline & $\mathbf{P}$ & 0.796 & 0.869 & 0.454 & - & - & - \\
\hline \multirow{2}{*}{ Received care } & $\mathbf{R}$ & 0.102 & 0.059 & 0.101 & 0.014 & - & - \\
\hline & $\mathbf{P}$ & 0.367 & 0.603 & 0.372 & 0.902 & - & - \\
\hline \multirow{2}{*}{ Professional quality } & $\mathbf{R}$ & 0.119 & 0.129 & 0.119 & 0.226 & 0.040 & - \\
\hline & $\mathbf{P}$ & 0.293 & 0.255 & 0.293 & $0.044^{*}$ & 0.727 & - \\
\hline \multirow{2}{*}{ Welcoming patients } & $\mathbf{R}$ & 0.014 & 0.104 & 0.027 & 0.090 & 0.065 & 0.335 \\
\hline & $\mathbf{P}$ & 0.902 & 0.358 & 0.815 & 0.430 & 0.569 & $0.002^{* *}$ \\
\hline
\end{tabular}

\section{Discussion}

Patient satisfaction is an indicator of the quality of care. Patient satisfaction is an attitude, a person's general orientation towards a total experience of health care. Without patient satisfaction there is no good care. Patient satisfaction should form part of continuous improvement. It is a method of evaluating the quality of health services provided to patients. Emergency care continue to be a challenge for pediatric patients. That is the reason why it is very important. A part from a good professional medical care, that mothers of children visiting a pediatric practice are satisfied in general. This study aims to assess children's satisfaction with emergency care from the mothers' perspectives.

Statistically significant differences regarding mothers satisfaction with nurses professional qualities was shown in the current study. Nearly half of the mothers mentioned that, nurses were efficient and, welcomed the children in a good manner. The findings of the 
present study are consistent with the study of Daniel I.(2012) who explored that patients' satisfaction with nursing care are variable, answerable, explainable, trustful, respectful, courtesy and available. The current findings support the importance of the interpersonal aspect of nursing practice. ${ }^{(20)}$ Previous studies conducted by Kane et.al(2007) (21) support the findings of the present study, he reported that patients expect several nursing qualities such as, kindness, quick responses to patients' needs, and availability of adequate time to provide nursing care.

The current study revealed that, slightly half of the mothers waiting in the ED, between $45<60$ minutes. The mean of waiting time was $51.31 \pm 19.61$ minutes. There is a negative correlation between mothers education, occupation and satisfaction with waiting time. A possible explanation of this finding could be, that the majority of parents tend to overestimate their waiting time and therefore, a consequence of long waiting time is a negative correlation to overall satisfaction. It could be also explained that negative correlation may be due to mothers occupation, that makethem busy and can't tolerate long waiting time.

The results of the present study is congruent with the study of Feddock CA et.al (2005) who reported significant negative correlation between parent satisfaction with the pediatric day center visit and waiting times. (22) The findings of the present study contradict with the study of Zahnarzt G.(2011) and the study of Anderson RT (2007) Who expected higher rate of satisfaction regarding waiting time. The mean waiting period in their study was 13,74 minutes, which is a suitable time in contrast to the average calculated waiting time of 28 minutes for pediatric day centers ${ }^{(23-25)}$

In the current study, three quarters of the mothers were satisfied by the nursing care and there is a statistical significant difference in the total nursing care and total teaching. Statistical significant correlation between the satisfaction of total care and mothers education was reported. It may be due to the natural positive relation between level of education and awareness, that make the educated mothers more appreciating to nursing 
performance. No significant correlation was found between mothers 'age and satisfaction with total care. Negative correlations also, observed between total care, total education and mothers' occupation. This negative correlations explain the fact that, with increase age and occupation there is a decrease on the patience and the ability to tolerate stressors. The pre-occupied mothers need high level of performance in a short time.

The results of the present study are congruent with the findings of Bacon \& Mark (2009) who reported that there is a correlation between patients' satisfaction and cultural background, age, and education. ${ }^{(26)}$ Other studies didn't find any relationship between patients' satisfaction and demographic variables, Laschinger et.al (2011). ${ }^{\text {(27) }}$

\section{Conclusion}

Mothers were generally satisfied with the care provided to their children by emergency nurses. Measuring patients' satisfaction with emergency nursing care remains a major challenge for health care providers. Patients' satisfaction has become an integral part of quality of pediatric emergency care. There is a significant difference regarding overall mothers' satisfaction with the total nursing care and total teaching provided to their children. Statistical significance correlation was found between the total care, total education and mothers' satisfaction with nurses professional characteristics.

\section{Recommendations}

1. Further researches are needed to capture children' opinions about the emergency care provided to them.

2. Application of triage system in emergency room to improve the quality of care.

3. Developing an educational program for nurses working in Emergency Department.

4. Enforcing patients' satisfaction as an indicator of the quality of nursing care provided in Emergency Department.

5. Further studies are needed to evaluate the effectiveness of triage nursing care in decreasing the health hazards resulting from delaying in nursing / medical interventions.

\section{Reference}

1. Lari M.A., Tamburini M. \& Gray D., Patients' needs, satisfaction, and health related quality of life: Towards a comprehensive model, 
Health and Quality of Life Outcomes 2004, 2:32. http://www.hqlo.com.

2. Taylor, C. \& Benger, J.R. Patient satisfaction in Emergency Medicine. Emergency Medicine Journal 2004, 12(3): 528-532.

3. Michael P. Simple tips to improve patient satisfaction, American Academy of Emergeny Medicine, 2011;18(1):18-19.

4. U.S. National Center for Health Services Research and Development: Computer simulation model for evaluation of the health care delivery system. Washington DC: US Government Printing Office; 1973.

5. Weissenstein A., Straeter A., et.al., Parent satisfaction with a pediatric practice in Germany: A questionnaire-based study, Italian Journal of Pediatrics, 2011, http://www.ijponline.net.

6. Amponsah E.N. Determinants of Consumer Satisfaction of Health Care in Ghana: Does Choice of Health Care Provider Matter?, Global Journal of Health Science, October, 2009: 1(2)50-61.
7. Abdel-Haq A, Paditz E, et.al., Internal Quality Assurance in the Children's Sleep Laboratory Surveying Parental Satisfaction with the 'Sleep Laboratory for Children Survey, Dresden' and Subsequent Optimization. Somnnologie 2005, 9:33-51.

Ojanen Thomas D. Special considerations for pediatric triage in the Emergency Department. Nurs Clin North Am. 2002;37:145159.

8. Middleton DR, Burt CW., Availability of pediatric services and equipment in emergency departments: United States, 20022003. Advance Data 2006; 367:116.

9. The Pediatric Emergency Care Project , Terminal Evaluation, www.jica.go.jp/egypt_2001.

10. Baillie L. An exploration of nursepatient relationships in accident and emergency. Accid Emerg Nurs. 2005;13: 9-14.

11. Nystrqm M, Nyden K, \& Petersson M. Being a non-urgent patient in an emergency care unit - a strive to maintain personal integrity. Accid 
Emerg Nurs. 2003;11:22-26.

12. Howard MS, Davis BA, et.al., Patients' perspective on choosing the emergency department for nonurgent medical care: a qualitative study exploring one reason for overcrowding. JEmerg Nurs. 2005;31: 429-435.

13. Lee G, Endacott R, \& Flett K, Bushnell R. Characteristics of patients who did not wait for treatment in the emergency department: a follow-up survey. Accid Emerg Nurs. 2006;14: 56-62.

14. Vieth TL, \& Rhodes KV. The effect of crowding on access and quality in an academic ED. Am J Emerg Med. 2006;24:787-794.

15. Schriver JA, Talmadge R, et.al., Emergency nursing: historical, current and future roles. J Emerg Nurs. 2003;29:431-439.

16. Elder, R., Neal, C., et.al., Patient satisfaction with triage nursing in a rural hospital emergency department. Journal of Nursing Care Quality19, 2004; 3: 263-268.

17. Davis, B.A., Bush, H.A. and Thomas, S.W. Measuring consumer satisfaction with emergency department nursing care. Journal of
Nursing Science, 1997;2(1-2):3547.

18. Saiboon I., Eng. Ho. Krishnan B., et al., A Study of Patients' Satisfaction with the Emergency Department (ED) of Hospital Universiti Kebangsaan Malaysia (HUKM), Med \& Health 2008; 3(1): 7-13.

19. Daniel I, The Relationship between Nurse Staffing and Patient Satisfaction in Emergency Departments, Institute of Health Policy, Management and Evaluation University of Toronto, 2012.

20. Kane, R. L., et.al. " Nursing Staffing and Quality of Patient Care." Evidence Report/Technology Assessment No. 151 Agency for Healthcare Research and Quality, 2007; 1-115.

21. Feddock CA, Hoellein AR, et.al., Can physicians improve patient satisfaction with long waiting times? Eval Health Prof 2005, 28:40-52.

22. ZahnarztG.,2011, [http://www.agzrnk.de/agz/content/2/ aktuelles/akt_00584.php],. 
23. Anderson RT, Camacho FT, \& Balkrishnan R: Willing to wait?: the influence of patient wait time on satisfaction with primary care. BMC Health Serv Res, 2007; 7:31.

24. Y F Choi, T W Wong, \& C C Lau, Triage rapid initial assessment by doctor (TRIAD) improves waiting time and processing time of the emergency department, Emerg Med J. 2006 April; 23(4): 262-265.

25. Bacon, C. T. \& Mark, B. "Organizational effects on patient satisfaction in hospital medicalsurgical units." Journal of Nursing Administration, 2009; 220-227.

26. Laschinger, H., Gilbert, S. \& Smith, L. "Nursing Outcomes; The State of the Science." Jones \& Barlett, Learning , 2011. 
